\title{
O processo de alfabetização: da pré-história da escrita a escrita simbólica
}

\author{
Lígia Márcia Martins', https://orcid.org/0000-0002-4293-9580 \\ Bruna Carvalho', https://orcid.org/0000-0003-3003-4589
}

Meire Cristina Santos Dangió ${ }^{1}$, https://orcid.org/0000-0002-2415-8510

\begin{abstract}
Resumo
Este artigo focaliza a alfabetização à luz da Psicologia Histórico-Cultural, estabelecendo relações entre a mesma e o desenvolvimento cultural do psiquismo destacando os vínculos existentes entre fala e escrita. Objetiva apresentar elementos que corroborem a compreensão dos processos psíquicos que medeiam a aprendizagem da escrita explorando o trânsito cultural que avança das expressões gráficas primevas, denominadas por Alexander Romanovich Luria como "pré-história da escrita", à escrita simbólica. Haja vista que o legado por este autor confere centralidade aos primórdios do desenvolvimento da escrita, identificamos na literatura histórico-cultural a existência de um hiato no tratamento dispensado, especificamente, à transição entre a pré-história e a escrita simbólica, dado que nos conduz à busca de aclaramentos sobre esta. Fundamentando-se no método materialista histórico-dialético, adotaram-se como procedimentos de pesquisa: análise conceitual do referencial bibliográfico adotado e contraposição da referida análise a dados empíricos advindos de registros de campo de duas professoras alfabetizadoras. Palavras-chave: Psicologia Histórico-Cultural; desenvolvimento humano; alfabetização.
\end{abstract}

\section{The literacy process: from the prehistory of writing the symbolic writing}

\begin{abstract}
This article focuses on literacy in the light of Historical-Cultural Psychology, establishing relationships between it and the cultural development of the psyche, highlighting the links between speech and writing. It aims to present elements that corroborate the understanding of the psychic processes that mediate the learning of the writing exploring the cultural traffic that advances from the primeval graphic expressions, denominated by Alexander Romanovich Luria like "prehistory of the writing", to the symbolic writing. Since the legacy of this author confers centrality to the early development of writing, we have identified in the historical-cultural literature the existence of a hiatus in the treatment, specifically, of the transition between prehistory and symbolic writing, since it leads us the search for clarifications about it. Based on the historical-dialectical materialist method, we adopted as research procedures: the conceptual analysis of the bibliographic references adopted and the analysis of empirical data derived from the field records of two literacy teachers,
\end{abstract}

Keywords: Historical-Cultural Psychology; human development; literacy.

\section{Proceso de alfabetización: de la pre-historia de la escritura a la escritura simbólica}

\section{Resumen}

En este artículo se focaliza la alfabetización a la luz de la Psicología Histórico-Cultural, estableciendo relaciones entre esta y el desarrollo cultural del psiquismo destacando los vínculos existentes entre el habla y la escritura. Se tiene por objetivo presentar elementos que corroboren a la comprensión de los procesos psíquicos que arbitran el aprendizaje de la escritura explotando el tránsito cultural que avanza de las expresiones gráficas primevas, denominadas por Alexander Romanovich Luria como "pre-historia de la escritura", a la escritura simbólica. Haya vista que el legado por este autor confiere centralidad a los principios del desarrollo de la escritura, identificamos en la literatura histórico-cultural la existencia de un hiato en el tratamiento dispensado, específicamente, a la transición entre la pre-historia y la escritura simbólica, dato que nos conduce a la búsqueda de aclaramientos sobre esta. Fundamentándose en el método materialista histórico-dialéctico, se adoptó como procedimientos de investigación: análisis conceptual del referencial bibliográfico adoptado y contraposición del referido análisis a datos empíricos advenidos de registros de campo de profesoras alfabetizadoras.

Palabras clave: Psicología Histórico-Cultural; desarrollo humano; alfabetización.

1 Universidade Estadual Paulista “Júlio de Mesquita Filho" - Araraquara - SP - Brasil; ligiamar@fc.unesp.br; brucarvalho.unesp@yahoo.com. br; meiredangio@gmail.com 


\section{Introduzindo a Questão: o Estado da Arte}

A alfabetização representa um dos grandes desafios a serem vencidos pela educação escolar, sobretudo a pública. Seu papel decisivo no percurso de escolarização dos indivíduos a coloca como objetivo nuclear do ensino e espinha dorsal da aprendizagem de todos os componentes curriculares. Não por acaso, democratizar o acesso à cultura letrada foi o objetivo originário da escola nos adventos da sociedade moderna (Saviani, 2012). Entretanto, consideramos que a existência de dificuldades para a efetiva realização desse ideal, especialmente nos países periféricos, se revela proporcional à sua importância. Este artigo visa apresentar elementos que corroborem a compreensão dos processos psíquicos que medeiam a aprendizagem da escrita à luz da Psicologia Histórico-Cultural, com especial destaque ao trânsito cultural que avança das expressões gráficas primevas, denominadas por Luria (2016) como pré-história da escrita, à escrita simbólica. Considerando que o legado deixado por esse autor confere centralidade aos primórdios do desenvolvimento da escrita, identificamos na literatura histórico-cultural a existência de um hiato no tratamento dispensado, especificamente, à transição da escrita pictográfica à escrita simbólica, dado que nos conduz à busca de aclaramentos sobre ela.

No que tange ao processo de alfabetização, somos anuentes à proposição de Martins e Marsiglia (2015, p. 73) ao definirem alfabetização como "... processo de apropriação de uma forma específica de objetivação humana: a escrita", o que nos remete ao destaque de dois conceitos: escrita e leitura. A escrita pode ser entendida como um instrumento de reprodução da fala humana. Contudo, ela é muito mais que a pintura da voz. Tornou-se a principal ferramenta do conhecimento, da ciência, da literatura, da informação popular via imprensa e uma arte em si (a caligrafia), além de outras manifestações (Fischer, 2009), mas ultrapassa as esferas destacadas pelo autor, conforme demonstram pesquisas neurocientíficas recentes, como a de Dehaene (2012) e Scliar-Cabral (1997), que evidenciam as expressões dos domínios da escrita na reconfiguração morfofuncional do cérebro humano. Não obstante, a maior parte dos indivíduos, sobretudo pertencentes às camadas populares, tem contato superficial com o sistema de escrita alfabética e, talvez, não tenha noção que o mundo da escrita representa muito mais do que combinação de consoantes e vogais que unidas formam palavras, que formam frases, que formam textos, que devem ser lidos da esquerda para a direita em linhas horizontais de cima para baixo (Fischer, 2009).

Sistemas de escritas foram elaborados, reelaborados e até mesmo extintos por diferentes povos e foram necessários mais de seis mil anos para que a escrita alcançasse o estágio no qual se encontra. Antes disso, o homem criou uma infinidade rica de símbolos gráficos e mnemônicos para acumular informações. A arte na pedra mostrou o repertório de símbolos (antropomorfos; fauna; flora; sol; cometas; desenhos geométricos, entre outros) criados pela humanidade para reproduzir fenômenos comuns do mundo. Além disso, outros elementos mnemônicos (como nós em cordas; marcas em ossos ou paus; tábuas etc.) relacionavam objetos ou fenômenos à fala (Fischer, 2009).

Essas criações do gênero humano (dos símbolos gráficos e mnemônicos ao sistema de escrita alfabética) foram elaboradas para comunicar, expressar ideias, contar fatos etc. Todavia, para que comuniquem verdadeiramente é necessário que tais símbolos sejam lidos e compreendidos. Dessa forma, podemos afirmar que a leitura é "... a capacidade de extrair sentido de símbolos escritos ou impressos [sendo que] o leitor emprega os símbolos para orientar a recuperação de informações de sua memória e, em seguida, cria, com essas informações, uma interpretação plausível da mensagem do escritor" (Mitchell, 1982 citado por Fischer, 2006, p. 11).

Sendo assim, a apropriação da escrita se torna um dos requisitos básicos para que os indivíduos se humanizem e conquistem pertença social efetiva, haja vista que ambas se firmam, cada vez mais, como lastros da sociedade moderna. Não por acaso, foi a invenção da escrita que demandou modos sistematizados de ensino, conduzindo ao surgimento da escola como instituição responsável pelo desenvolvimento, nos indivíduos, da capacidade de leitura e escrita. A cada nova geração é necessário ensinar o funcionamento do sistema de escrita adotado para que esta objetivação humana continue viva ao ser utilizada por elas. "A alfabetização é, pois, tão antiga quanto os sistemas de escrita. De certo modo, é a atividade escolar mais antiga da humanidade" (Cagliari, 2009, p. 14) e, certamente, a mais importante função da escola, já que outros processos de aprendizagem são dependentes dela.

Todavia, no âmbito dessa importante função a escola tem mostrado limites, conforme dados que se revelam alarmantes ao apontarem o elevado número de indivíduos que mesmo frequentando a escola permanecem analfabetos ou se tornam analfabetos funcionais. Os resultados da Avaliação Nacional da Alfabetização (ANA) ${ }^{1}$ obtidos em 2014 apontam que somente $11,2 \%$ dos alunos avaliados apresentaram nível de leitura e escrita esperado para o ano avaliado (Instituto Nacional de Estudos e Pesquisas Educacionais Anísio Teixeira, 2014). Ademais, pesquisas do Instituto Brasileiro de Geografia e Estatística (IBGE) evidenciam que apesar de a porcentagem de analfabetos estar diminuindo, uma vez que pouco mais de $8 \%$ da população brasileira acima de 15 anos permanece analfabeta, os resultados gerais ainda estão distantes do ideal. Além disso, o analfabetismo funcional permanece como característica de mais de $20 \%$ dos brasileiros (Instituto Brasileiro de Geografia e Estatística, 2015). Segundo resultados do Indicador de Analfabetismo Funcio-

\footnotetext{
1 A Avaliação Nacional da Alfabetização (ANA) é uma avaliação externa que objetiva aferir os níveis de alfabetização e letramento em Língua Portuguesa (leitura e escrita) e Matemática dos estudantes do $3^{\circ}$ ano do Ensino Fundamental das escolas públicas. As provas aplicadas aos alunos forneceram três resultados: desempenho em leitura, desempenho em matemática e desempenho em escrita (Instituto Nacional de Estudos e Pesquisas Educacionais Anísio Teixeira, 2015).
} 
nal (INAF), pouco mais de um quarto da população brasileira tem nível pleno de habilidades esperado ao completar os nove anos do ensino fundamental. $E$ os dados da pesquisa se mostram mais alarmantes quando revelam que somente $62 \%$ das pessoas com ensino superior e $35 \%$ das pessoas com ensino médio completo são classificadas como plenamente alfabetizadas (Instituto Paulo Montenegro, 2011), ou seja, são capazes de ler e interpretar textos mais longos, analisar e relacionar suas partes, realizar inferências e sínteses, além de resolver problemas que exigem maior planejamento e controle. Em suma, no âmbito da alfabetização ainda são inúmeros os déficits da educação escolar, desde a educação infantil ao ensino superior.

Contudo, não desconsideramos que a discussão sobre a incapacidade da escola em dar conta de sua tarefa histórica (ensinar todos a ler e a escrever) não é exclusividade de nosso tempo. O que hoje chamamos de "fracasso escolar" tem mobilizado desde o final do século XIX governantes, legisladores do ensino, intelectuais, pesquisadores e professores (Mortatti, 2000). Reconhecemos os inúmeros esforços político-administrativos nacionais, tanto em nível federal quanto estadual, em direção ao enfrentamento dessa problemática ao investirem, sobretudo, em cursos de capacitação para professores alfabetizadores. Na esfera federal, foram criados pelo Ministério da Educação (MEC): o Programa de Formação de Professores Alfabetizadores (PROFA) (1999-2000); o Programa Brasil Alfabetizado (PBA) (2001); o Pró-Letramento (2006) e o Pacto Nacional pela Alfabetização na Idade Certa (PNAIC) (2013). No âmbito do Estado de São Paulo, podemos citar o Programa Ler e Escrever (2007), da Secretaria Estadual da Educação. Apesar de todas as ações e políticas implantadas objetivando a erradicação do analfabetismo,a universalização da alfabetização ainda se impõe como problema nacional. Diante desse cenário, visamos apontar contribuições da Psicologia Histórico-Cultural para o processo de alfabetização e, para tanto, apresentaremos inicialmente as articulações entre o processo de aquisição da fala e da escrita. Na sequência, explanaremos sobre as etapas da pré-história da escrita: pré-instrumental; escrita gráfica diferenciada, escrita pictórica e escrita simbólica. Para finalizar, lançaremos proposições acerca do interstício entre a escrita pictográfica em direção à escrita simbólica.

\section{Da Fala à Escrita: Articulações entre Linguagem Oral e Linguagem Escrita}

Na psicologia histórico-cultural, a capacidade para a leitura e a escrita se revelam umbilicalmente dependentes de um processo mais amplo, qual seja, o desenvolvimento do psiquismo. Caracterizando o psiquismo como um sistema instituído pelas funções psicofísicas sensação, percepção, atenção, memória, linguagem, pensamento, imaginação, emoção/ sentimentos, a quem compete formar o reflexo consciente da realidade objetiva (Martins, 2013), essa matriz teórica advoga a apropriação da cultura como o fator que, decisivamente, transforma as referidas funções conferindo-lhes propriedades exclusivamente humanas. Dentre tais propriedades destacam-se a acuidade perceptual simbólica, a atenção focal, a memória lógica, a criação e domínio de signos, o raciocínio, a criatividade, a valoração afetiva etc., instituindo o comportamento humano como ato cultural voluntário e sob controle de finalidades conscientes específicas. Haja vista que a formação dessas propriedades não resulta de dispositivos inatos, mas das demandas da vida social, a educação desponta como processo ontologicamente necessário à humanização do psiquismo e, consequentemente, de sua qualidade depende a referida formação. Resulta, pois, inquestionável que a aprendizagem da leitura e da escrita se subordine à conquista de tais propriedades funcionais, dado que nos conduz à afirmação segundo a qual a alfabetização, de partida, é uma conquista condicionada pelo processo de formação de um psiquismo complexo, tipicamente humano, cujo principal atributo se revela na capacidade de abstração. Interessa-nos, com tais observações, localizar a alfabetização no bojo de um processo mais amplo, qual seja o desenvolvimento psíquico, com o qual ela estabelece uma relação de condicionalidade recíproca. Assim, defendemos que a aprendizagem da leitura e da escrita possui suas raízes na formação cultural do psiquismo, antecipando-se, em muito, aos atos pedagógicos voltados especificamente para esse fim.

Apreendendo o psiquismo humano como formação cultural, nela destacam-se três grandes saltos qualitativos: o desenvolvimento da fala, a aquisição da escrita e a conquista do pensamento rigorosamente abstrato, que marca a transição à idade adulta (Vygotsky, 2001). Nossa atenção volta-se para os dois primeiros marcos qualitativos, ou seja, para as articulações entre a aquisição da fala e da escrita. Antes, porém, cabe apresentar os conceitos de fala, língua e linguagem tal como proposto por Luria (1981).

A fala é um meio especial de comunicação vocal e oral que usa a linguagem para transmitir informações. Já a língua é constituída por vocabulário, gramática e sistemas fonológicos específicos, instituindo-se como um sistema particular de comunicação por meio da linguagem. A linguagem, por sua vez, é um sistema de signos que opera como um meio de comunicação e trocas entre os indivíduos, além de ser um instrumento do pensamento. Graças a ela, a imagem subjetiva dos objetos e fenômenos que constituem a realidade objetiva pode ser convertida em signos e, a partir deles, generalizada sob a forma de ideias, de conceitos (Martins, 2013).

Visando explicitar as articulações entre fala e escrita, colocaremos em foco três questões: desenvolvimento da linguagem oral e construção do significado da palavra; linguagem interna como intermédio entre linguagem oral e linguagem escrita e, por fim, características essências da linguagem escrita. No que tange ao desenvolvimento da linguagem, Vygotsky (1995) afirma que ela é uma das funções mais importantes na história do desenvolvimento das funções psíquicas, posto sintetizar o acúmulo da experiência social da humanidade, bem como possibilitar que as objetivações humanas possam ser transmitidas de geração a geração. Por isso, dela resultam os mais decisivos avanços qualitativos do psiquismo humano, tanto do ponto de vista 
filogenético quanto do ontogenético. Com base em Vygotsky e Luria (1996), Martins (2013, p.168) afirma: "Ao representar os objetos e fenômenos por meio da palavra, o homem deu o primeiro e mais decisivo passo em direção ao desenvolvimento da sua capacidade para pensar", haja vista que no âmbito sensório-perceptual, toda captação é particular, entretanto, no âmbito das designações, das representações por meio de signos, toda percepção se torna generalização. Assim, a palavra, além de se instituir como forma de comunicação, expressão e mecanismo de influência sobre o outro, tornando-se o mais importante e peculiar instrumento das relações entre os seres humanos, no exercício de sua função generalizadora se converte em instrumento decisivo do pensamento. Martins (2013, p. 169) explica ainda que:

... a função comunicativa primária da palavra é o controle do comportamento do outro. Orientando-se para o exterior, ela visa, no ponto de partida, à influência sobre outras pessoas, dirigindo-lhes a ação. Entretanto, é exatamente no exercício dessa função que a palavra se transforma. Da mesma maneira que os demais processos, a linguagem aparece primeiramente como processo interpessoal para, na sequência, instalar-se como manifestação intrapessoal, intrapsíquica.

Sendo assim, o desenvolvimento da linguagem acontece a partir do plano interpsíquico, isto é, das relações sociais, e pela via da internalização se firma no plano intrapsíquico. A apropriação dessa objetivação humana ancora-se, por conseguinte, nas relações entre os indivíduos e, a partir delas, se impõe como instituinte do psiquismo de um sujeito particular. Esse processo de internalização atende um longo percurso de formação, pelo qual a palavra vai se consolidando, ao mesmo tempo, como componente nuclear tanto da fala quanto do pensamento porque, segundo Vygotsky (2001), fala e pensamento, em suas origens, seguem linhas distintas de formação e desenvolvimento; todavia: “... em um determinado momento, na idade infantil, até os dois anos, as linhas do desenvolvimento do pensamento e da fala, até então independentes uma da outra, se encontram e coincidem, iniciando uma forma totalmente nova de comportamento, exclusivamente humana" (p. 172). Graças a esse entrecruzamento é que a palavra vai deixando de ser mera extensão ou representação verbal do objeto e, ultrapassando a conexão direta objeto-designação, promove a conversão da imagem do objeto em ideia, em conceito. Por essa via, a palavra se institui como fenômeno verbal e intelectual.

Ao destacarem a palavra como fenômeno verbal e intelectual, Vygotsky (2001) e Luria (1979) postulam nela a existência de duas faces: a fonética e semântica. A primeira compreende o lado externo, verbal, que lhe possibilita ocupar mentalmente o lugar de dado objeto ou fenômeno. A face semântica, voltando-se à significação da palavra, visa a análise dos objetos, distinguindo suas características essenciais e instituindo-os como integrantes de dadas categorias. Em sua face semântica a palavra desponta como instrumento psíquico de generalização e abstração, pelas quais os próprios significados das palavras se ampliam, transformando significações mais diretas e imediatas em conceitos mais gerais e abstratos. Segundo Luria (1979):

... cada palavra de uma língua evoluída oculta um sistema de ligações e relações nas quais está incluído o objeto designado pela palavra e de que 'cada palavra generaliza' e é um meio de formação de conceitos, noutros termos, deduz esse objeto do campo das imagens sensoriais e o inclui no sistema de categorias lógicas que permitem refletir o mundo com mais profundidade do que o faz a nossa percepção... Eis porque a palavra não apenas significa uma imagem, mas também inclui o objeto no riquíssimo sistema de ligações e relações em que ela se encontra. (Luria, 1979, p.35)

Colocando em relevo as transformações dos significados das palavras, o autor indica a transição de significações mais diretas e imediatas para conceitos mais gerais como condição para o enriquecimento tanto da fala quanto do pensamento. Afirma que o conceito mais geral, representado mais abstratamente pela palavra, contém interiormente um sistema de relações indispensável ao movimento do pensamento. Ilustra essa assertiva tomando como referência primária uma dada palavra em sua função denominadora direta, a exemplo de "pinheiro", a ser então indutora de outra, "vegetal". A segunda palavra, do ponto de vista do grau de concreticidade, mostra-se mais pobre que a primeira. Entretanto, ao conter uma rede de ligações internas, tais como as diferenças entre vegetal e animal, os diferentes tipos de vegetal, as propriedades que dispõe etc., ausentes na palavra "pinheiro", ela mostra-se incomensuravelmente mais rica do ponto de vista da formação da capacidade de pensar. Por isso, destaca o autor, a palavra que promove a formação de conceitos, muito mais do que aquela que corresponde à captação sensorial imediata do objeto, representa o mecanismo mais decisivo do movimento do pensamento desenvolvido.

Segundo Luria (1981), o tratamento dispensado à ampliação do significado da palavra demanda que se leve em conta as características de sua integração ao processo de fala. Com esse intuito o autor destaca que a execução da fala abarca três componentes: o mecanismo acústico; a organização léxico-semântica e a sintaxe. O primeiro corresponde à conversão de um fluxo de sons em fonemas, ou seja, no isolamento e posterior aglutinação de sons pelos quais os mesmos conquistam significação. Já o segundo diz respeito ao domínio do código lexical da língua, por meio do qual são estabelecidas as correspondências entre as imagens mentais da realidade e seus equivalentes verbais, conferindo funcionalidade às palavras. Este domínio possibilita a designação de objetos e fenômenos em um sistema de conexões morfológicas e semânticas. Tais conexões são requeridas à sintaxe, último componente, que se manifesta nas formas de frases, necessárias à narrativa falada, demandando a consolidação da linguagem gramatical. Apesar das variações em seu grau de complexidade, a sintaxe é sempre condicionada pela transição do pensamento em fala. 
Portanto, o percurso de desenvolvimento da fala conclama radicalmente o pensamento e, pela construção das alianças entre ambos a palavra vai se consolidando, cada vez mais rigorosamente, como ato de pensamento. Ao colocar esse percurso como objeto de análise Vygotsky (2001) constata a existência de equívocos nas interpretações segundo as quais o desenvolvimento da fala caminha da parte para o todo. Levando em conta que a formação das funções psíquicas complexas não segue uma linha reta de desenvolvimento, o autor alerta, no âmbito da formação da linguagem oral, para a importância do aspecto semântico, cuja centralidade identifica-se à dinâmica do todo para as partes. Apesar do desenvolvimento da linguagem oral seguir o percurso "palavra-frase-orações-complexo sistema de fala" mesmo na pronúncia de uma única sílaba dotada de significado pode estar condensada não só uma palavra, mas uma frase e até mesmo uma oração. A fala se torna técnica de expressão do pensamento a partir do aprendizado do significado e controle da palavra visando à realização de dados objetivos.Vygotsky e Luria (1996, p. 210) explicam que:

Tendo compreendido o significado de uma palavra, como forma de expressão, como um meio de adquirir controle sobre as coisas que lhe interessam, a criança começa a juntar palavras tumultuadamente e a utilizá-las com esse objetivo. A palavra 'babá' não significa somente babá para a criança: significa 'babá venha aqui', ou 'babá, vá embora', ou 'babá, me dê uma maçã'. Dependendo das circunstâncias, pode adquirir sentidos diferentes, mas aparece sempre em sua forma ativa que expressa, numa única combinação de sons, todo o desejo da criança. O primeiro período do uso significativo da fala é sempre um período de sentenças de uma só palavra.

Ao ultrapassar o fim exclusivamente expressivo a fala passa a ter também função no planejamento e na orientação do comportamento, sinalizando a mudança da linguagem em sua prevalência interpsíquica à primazia intrapsíquica. Esta conquista, segundo Vygotsky e Luria (2007), corresponde ao surgimento da fala egocêntrica.

A maior mudança produzida no desenvolvimento da criança se dá quando essa fala socializada, anteriormente dirigida ao adulto, se volta para si mesma, quando, em lugar de apelar ao experimentador com um plano para resolver o problema, a criança apela a si mesma. Nesse segundo caso, a fala que intervém na solução passa desde a categoria de função interpsíquica à de função intrapsíquica. A criança aplica a si mesma o método do comportamento que antes aplicava ao outro, organizando assim sua conduta individual segundo a forma social de conduta. A fonte da atividade intelectual e do controle sobre seu comportamento na resolução de problemas práticos complexos não é consequentemente a invenção de algum tipo de ação lógica pura, mas a aplicação de uma atitude social para consigo mesmo, a transferência de uma forma social de conduta na organização de sua própria psique. (Vygotsky \& Luria, 2007, p. 32, grifos dos autores).
Com o desenvolvimento psíquico, a criança aos poucos vai parando de vocalizar o pensamento consigo mesma para resolver ou executar alguma atividade em que está envolvida, passando a conduzir sua conduta pela linguagem interna, ou seja, ela pensa as palavras sem dizê-las. A fala egocêntrica marca a transição da linguagem externa em interna. Vygotsky (2001) afirma que essa transição é imprescindível para o desenvolvimento dos comportamentos culturalmente formados, além disso, frisa que a função da linguagem interna é altamente especializada e distinta em relação à linguagem oral. Contrapondo-se à ideia de que a linguagem interna represente meramente a linguagem externa carente de som, o autor postula que o traço distintivo central entre elas reside na redução fonética quase absoluta que se verifica na linguagem interna. Por detrás dessa redução se estabelecem relações diferentes entre os aspectos semânticos e fonéticos, prevalecendo, na linguagem interna, o sentido sobre o significado da palavra, isto é, os aspectos semânticos se sobrepõem aos aspectos sonoros e fonéticos. O sentido da palavra é dinâmico, variável e sempre depende do contexto de aplicação, entretanto, o significado da palavra é, diferentemente, mais estável, coerente e preciso, sofrendo poucas variações mesmo nos casos de mudança de sentido. Por conseguinte, o real significado da palavra revela-se como possibilidade de vir a ser, haja vista que o significado não é dado na palavra mesma, mas no contexto da frase que integra. Logo, "na linguagem interna, o predomínio do sentido sobre o significado, da frase sobre a palavra e do contexto sobre a frase não é uma exceção, mas sim a regra geral" (Vygotsky, 2001, p. 334).

Conforme o autor, outra característica da linguagem interna refere-se à combinação ou fusão de palavras. Por um lado, verifica-se na linguagem interna o fenômeno da aglutinação de determinadas palavras como procedimento para compor outras, aptas a expressar conteúdos complexos. A palavra composta, ao cumprir essa tarefa, se manifesta funcional e estruturalmente como uma palavra e não como locução. Assim, ocorre uma unificação não apenas entre palavras, mas, sobretudo entre os sentidos que adquirem, quando entre eles se estabelece uma influência mútua da qual resulta, inclusive, o significado conferido à palavra. Considerando que a fala interior se coloca a serviço do pensamento, sua transmutação sob a forma de linguagem oral demandará mudança do papel da palavra, pela qual a função generalizadora deva ceder lugar, novamente, à função comunicativa. Sem esta mudança a oralização da fala interior resulta compreensível para quem fala, mas incompreensível para quem ouve.

O autor destacou, assim, as enormes diferenças entre a linguagem interior e externa, estabelecendo uma aproximação entre a linguagem interior e a linguagem escrita, que são fundamentalmente monológicas, diferentemente da linguagem oral, dialógica, caracterizada essencialmente pela relação com o interlocutor. $\mathrm{Na}$ linguagem exterior, a transmissão direta do pensamento não se restringe ao uso de palavras, condicionando-se pelo conhecimento existente entre os envolvidos nela, pela entonação adotada, bem como 
gestos e expressões faciais. Esse conjunto de fatores permite a afirmação da existência de aglutinações também na linguagem exterior, não obstante tratar-se de uma simplificação de caráter distinto daquele que é próprio à linguagem interna. Para Vygotsky (2001, p. 327) a linguagem escrita, ao objetivar a linguagem interior, representa "... a forma mais elaborada, mais exata e mais completa de linguagem, posto que nela o pensamento deva expressar-se completamente nos significados formais das palavras adotadas e pela precisão sintática". O autor chama atenção para a necessidade de compreensão da linguagem escrita como aquisição psicológica complexa, isto é, como conquista instrumental do psiquismo e não como um hábito motor específico. Considerou que o problema da linguagem escrita ainda era insuficientemente estudado pela psicologia e, consequentemente, essa importante aquisição permanecia subjugada a uma diversidade imensa de teorias pedagógicas de parcos fundamentos científicos. Ele defendeu que a aquisição da leitura e da escrita não corresponde à instalação de comportamentos externos, mecânicos, determinados "desde fora", não se identifica com a conquista de habilidades psicofísicas nas quais a motricidade da escrita e a decodificação das letras possa se destacar em detrimento dos conteúdos internos das mesmas, postulando que: “... é preciso ensinar à criança a linguagem escrita e não a escrita das letras" (Vygotsky, 2006, p. 203). A apropriação da linguagem escrita representa para a criança o domínio de um sistema simbólico altamente complexo e dependente, em alto grau, do desenvolvimento do psiquismo, sobretudo no que se refere à formação da capacidade abstrativa. Por isto, Vygotsky $(1995,1997,2006)$ e Luria $(1981,2001)$ consideram que a aprendizagem da escrita principia muito antes do momento em que se coloca um lápis na mão da criança tendo em vista ensiná-la a escrever. Os processos de percepção, atenção, memória, linguagem oral, pensamento e sentimentos configuram o todo a partir do qual a linguagem escrita se edifica. Por isso, indicam os autores, o êxito nessa aquisição não é um dado circunscrito ao momento no qual se ensina a criança a escrever nem subjugado meramente às estratégias para alfabetização, mas profundamente dependente daquilo que eles denominaram como pré-história da linguagem escrita. Nessa direção, “... para que a linguagem escrita da humanidade se converta na linguagem escrita da criança são necessários complexos processos de desenvolvimento" (Vygotsky, 1995, p. 185).

Com vista à exposição dos momentos mais decisivos que preparam esse complexo desenvolvimento, o autor destaca a importância do gesto, que no plano gráfico corresponde à garatuja, dos jogos simbólicos, do desenho e dos próprios primórdios da escrita. Tais proposições vigotskianas balizam o tratamento dispensado por Luria (2016) acerca da pré-história da escrita, questão que versamos na sequência.

\section{A Pré-História da Escrita e a Transição da Etapa Pictórica à Escrita Simbólica}

Vygotsky (1995) e Luria (2016) conduziram-se, no âmbito da linguagem escrita, a investigações acerca de sua pré-história, colocando em destaque as relações entre o pensamento infantil e a utilização de expedientes gráficos desde uma relação externa até uma relação funcional com a palavra escrita. Com este intuito Luria (2016, p. 144) procede a análises visando “... descrever os estágios que nós observamos quando uma criança desenvolve sua habilidade para escrever e os fatores que a habilitam a passar de um estágio para o outro, superior". Quando a criança começa a se relacionar com a linguagem escrita, ela passa a mobilizar todo um sistema de formas intelectuais de comportamento pelo qual deverá controlar suas atividades gráficas. Todavia, o autor pondera que esta relação atende, em suas origens, a duas condições:

Em primeiro lugar, as relações da criança com as coisas a seu redor devem ser diferenciadas de forma que tudo o que ela encontra inclua-se em dois grupos principais: a) ou as coisas representam algum interesse para a criança, coisas que gostaria de possuir ou com as quais brinca; b) ou os objetos são instrumentos, isto é, desempenham apenas um papel instrumental ou utilitário, e só têm sentido enquanto auxílio para a aquisição de algum outro objeto ou para a obtenção de algum objetivo, e, por isso, possuem apenas um significado funcional para ela. Em segundo lugar, a criança deve ser capaz de controlar seu próprio comportamento por meio desses subsídios, e nesse caso eles já funcionam como sugestões que ela mesma invoca. (Luria, 2016, p. 145).

A partir disto, ele realizou experimentos nos quais ditava frases às crianças não alfabetizadas para que elas anotassem como signos auxiliares da memória e constatou a existência de diferentes maneiras pelas quais elas se utilizavam de marcas gráficas e, com base nessas formas típicas e distintas, o autor propôs os seguintes estágios: pré-instrumental, escrita gráfica não diferenciada, escrita gráfica diferenciada e escrita pictográfica, considerando-os representativos da pré-história da escrita e precedentes ao estágio da escrita simbólica. Num primeiro estágio verificou a existência de um processo de imitação da escrita em que os sujeitos pesquisados demonstraram apenas uma relação externa com a escrita e, muitas vezes, grafar no papel o que era ditado representava obstáculo para o registro mnêmico. $O$ que eles produziam eram rabiscos em forma de ziguezague, não mantendo relações com a frase ditada. Conforme Luria (2016, p. 150): “... a criança toma sua forma externa e acredita ser capaz de escrever, antes mesmo de saber o que deve ser escrito". Isto caracteriza a fase pré-instrumental. Para superá-lo a criança deverá estabelecer uma relação sígnica com as marcas no papel, ou seja, o que foi grafado deve expressar um conteúdo específico que possa ser recuperado posteriormente. Portanto, outro momento da pré-história da escrita efetiva-se quando a criança produz marcas topográficas na folha de papel para lembrar-se do que foi ditado a ela. Este é o estágio da escrita não diferenciada. Nele, há o emprego de uma forma primitiva de escrita que, apesar de serem marcas não-diferenciadas, apresentam-se repletas de funcionalidade. Esse é um momento importante no desenvolvimento da 
escrita, pois "... é o primeiro rudimento do que mais tarde se transformará na escrita, na criança; nele vemos, pela primeira vez, os elementos psicológicos de onde a escrita tirará forma" (Luria, 2016, p. 158).

Com a maior objetividade às marcas gráficas e com o uso na condição de signos, tem início o estágio da escrita gráfica diferenciada, na qual os registros gráficos são utilizados para relembrar a frase ditada. Este estágio ainda não revela diferenças externas significativas em relação à anterior, contudo os rabiscos passam a ter uma função específica no ato de memorização. Neste estágio a criança percebe as relações entre a escrita como forma de registro e de ampliação da sua capacidade para memorizar. O autor buscou descobrir qual seria o fator impulsor dos avanços subsequentes e que culminariam na capacidade de escrever e constatou que o conteúdo do que era apresentado fazia grande diferença, pois induzia o tipo de marca a ser feito. Quando solicitado às crianças que registrassem quantidades e formas, isso fazia com que elas representassem o que estava sendo ditado inicialmente por traços diferenciados e depois por meio de desenhos. Com a adoção do desenho como forma de registro principia, então, o estágio da escrita pictórica. "O desenho transforma-se, passando de simples representação para um meio, e o intelecto adquire um instrumento novo e poderoso na forma da primeira escrita diferenciada" (Luria, 2016, p. 166). Aqui, a criança passa a fazer uso do desenho como um expediente auxiliar e não apenas como uma brincadeira. Todavia, Vygotsky (1995) e Luria (2001) destacaram que na imensa importância dessa conquista, existe uma diferença radical entre o desenho e a escrita, posto que na estrutura interna do desenho infantil radica uma relação direta entre a representação gráfica e dado conteúdo sensível, ou seja, a criança desenha "coisas" e não palavras. Diferentemente, a escrita não se estrutura em uma relação direta com o objeto, mas com a palavra que o designa. Daí que a linguagem oral esteja para a representação do objeto tanto quanto a linguagem escrita está para a linguagem oral. Sendo assim, o avanço do estágio da escrita pictográfica em direção à escrita simbólica subordina-se à capacidade abstrativa da criança, pela qual ela apreende que o ato de escrever é guiado pela palavra a ser escrita. Contudo, a compreensão da linguagem escrita por meio da linguagem oral, caracteriza os primórdios da fase da escrita simbólica, uma vez que o pleno domínio da escrita demanda fusão entre ambas, pela qual a escrita passa a objetivar a linguagem interna firmando-se como ato efetivamente simbólico. Luria (2001) destaca, ainda, que a despeito de uma aparente linearidade no desenvolvimento da escrita, sua dinâmica interna encerra inúmeras rupturas e saltos qualitativos, que são produzidos quando se passa de um estágio para outro. A nosso juízo, um dos grandes saltos ocorre na viragem da escrita pictográfica para a escrita simbólica, representando um momento crucial para a formação do simbolismo da escrita; questão sobre a qual discorremos na sequência.

\section{Transição entre o Estágio Pictográfico e a Escrita Simbólica: Apontamentos}

No desenvolvimento da escrita há graduações na utilização e diferenciação das marcas gráficas e dos símbolos, além de mudanças das técnicas adotadas pelas crianças, que vão desde rabiscos e linhas, passando por figuras, imagens e registros gráficos com letras. Todavia, os meandros da viragem entre o estágio pictográfico e a escrita simbólica não foram aprofundados na caracterização luriana, dado que nos conduziu à análise ${ }^{2}$ do desempenho de crianças em situações reais de alfabetização tendo em vista aclarar este interstício. Considerando que esta transição ocorra, em geral, entre os anos finais da educação infantil e anos iniciais do ensino fundamental, entendemos que ela tenha grandes implicações para o processo de alfabetização neste período.

As análises do desempenho de crianças neste período possibilitaram-nos constatar que o estágio pictográfico se encaminha para o estágio da escrita simbólica pela mediação de duas subetapas, as quais denominamos como pré-gráfica e subetapa do simbolismo gráfico. Na subetapa pré-gráfica a descoberta da criança é a de que a cada palavra corresponde uma representação gráfica, tal como outrora, no âmbito do desenvolvimento da fala, descobrira que a cada objeto correspondia determinada denominação. A referida descoberta representa um significativo avanço na capacidade de abstração da criança, contudo, ela não possibilita, ainda, quaisquer relações estáveis entre sons e símbolos. Da mesma forma que a relação entre percepção do objeto, representação mental do mesmo e som correspondente operou decisivamente na formação da palavra, esta relação, agora, atua também para os necessários avanços na subetapa pré-gráfica. No que tange à percepção, a criança precisa captar e discriminar os tipos de sons que emite para que, a partir de então, Ihe seja apresentada a grafia do som. Trata-se de recuperar a ênfase no mecanismo acústico da fala, pelo qual o isolamento e posterior aglutinação de sons, conquistou a forma de fonemas, transpondo-os para seus correlatos gráficos sob a forma de letras. $O$ percurso de ensino tem, tal como na pré-história da escrita, a fala como ponto de partida e de referência concreta para a criança e, a partir dela, se deve extrair o pareamento entre som e letra como unidade de análise da palavra. A palavra deve ser submetida à análise, isto é, deve ser decomposta pelos sons que a compõem, a serem representados por letras em suas formas gráficas correspondentes. O alvo do ensino na subetapa pré-gráfica é a ampliação do domínio lexical da língua corroborando correspondências entre os fonemas e os grafemas, com destaque às suas dimensões morfológicas e semânticas. É, pois, firmando tais relações que ocorre a gradativa superação desta subetapa, à medida que a criança vai aprendendo que a cada som corresponde um tipo de símbolo.

Nesse momento ela reproduz letras, algumas inclusive acertadas em relação à palavra a ser escrita, mas o faz

2 Tais análises advêm do trabalho de duas das autoras como professoras alfabetizadoras e pesquisadoras sobre o tema. 
ainda na base de uma conexão aleatória, entre fonemas e grafemas. A escrita representativa da subetapa pré-gráfica, com base na conexão externa entre fonemas e grafemas, pode ser demonstrada por situações nas quais crianças escrevem ou leem silabando corretamente uma palavra, no entanto, quando perguntadas acerca do que escreveram ou leram não conseguem dizer. Em situações reais de análise, encontramos ocorrências do tipo:ao pedirmos à criança para escrever, por exemplo, a palavra "cavalo", ela escreve corretamente e quando solicitada a leitura, lê silabando "ca-va-lo". Todavia, diante da pergunta: qual palavra você leu, ela diz não saber ou diz outra palavra, como verificado no caso de uma criança que após ler silabando corretamente a palavra "rato", e lhe ter sido perguntado qual palavra era formada por "ra+to", a resposta foi "coelho". Vemos que, não obstante a descoberta de que existe uma relação entre fonemas e grafemas, a criança ainda não domina os procedimentos requeridos às generalizações entre sons e símbolos, dado que não lhe permite, ainda, a escrita autônoma. Para tanto, ela precisa ultrapassar a conexão aleatória fonema/grafema convertendo o som em signo. Trata-se, pois, da compreensão do significado das letras e das sílabas tanto na articulação da fala quanto da escrita. Por essa via a criança adentra à subetapa seguinte, que diz respeito à formação, propriamente dita, do domínio do sistema simbólico da escrita, e por isso a denominamos como 'subetapa do simbolismo gráfico'. Tal como no desenvolvimento da fala, esta subetapa abarca os mecanismos acústicos necessários à organização léxico-semântica e a sintaxe, próprias à etapa da escrita simbólica. O domínio do mecanismo acústico possibilita à criança a identificação da correspondência entre fonemas e grafemas bem como a correspondência entre o grafema e o código léxico. Para tanto, os sons são isolados mentalmente e sequencialmente aglutinados, conquistando significação fonética que orienta a transposição do fonema em grafema, caminhando para a consolidação das relações grafofônicas. Todavia, a escrita se faz marcada por erros gramaticais; ortográficos e por dificuldades nas sílabas não-canônicas, a exemplo de fãtazia para fantasia; caza para casa; abela para abelha etc. Essa etapa encerra alta complexidade e, podemos dizer, representa o divisor de águas entre a pré-história da escrita e a escrita simbólica gramatical. Mas nela, ainda predominam as ações em detrimento das operações de escrita e a sua superação consiste exatamente na inversão desta prevalência. Apoiados em Leontiev (1978), consideramos que as ações representam os componentes ou elementos intermediários na atividade de escrita, e são mobilizadas por uma finalidade específica e conscientemente orientada. Sob prevalência da ação, a criança atua decompondo cada uma das letras ou sílabas que compõem a palavra, fazendo-o, não raro, em voz alta, com a finalidade de, parte a parte, encontrar seu correspondente gráfico. Trata-se, pois, da realização de uma série de ações cuja finalidade é o pareamento adequado entre os sons e seus símbolos gráficos. As ações são também prevalentes no âmbito da leitura, posto que a consciência da criança, nesta subetapa, subjuga-se à decodificação da relação entre grafema e fonema, o que ocorre, via de regra, em detrimento do significado da palavra. Portanto, apenas o automatismo desta relação poderá transformar as ações de escrita e de leitura em operações automatizadas, redirecionando a consciência para o universo de significados grafados por meio das palavras e, igualmente, para o uso da escrita como registro do pensamento. Para tanto, destaca-se a importância dos treinos que visam o automatismo, sem o qual nenhuma ação se converte em operação. Daí a necessidade da repetição, requerida à memorização da relação fonema/grafema, bem como da criação do hábito de escrita, conferindo ênfase aos aspectos técnicos do ato de escrever que, diga-se de passagem, muitos alfabetizadores tendem a abolir em nome de uma possível descoberta espontânea por parte da criança. Quando as ações se convertem em operações de escrita tem início a escrita simbólica, predominantemente marcada pelos domínios léxicos e gramaticais da língua. O salto qualitativo presente nesta etapa é o alcance da atividade de escrita, pela qual ocorre a conversão da linguagem interna em linguagem externa gráfica, atendendo aos determinantes do pensamento e das regras gramaticais da língua.

Destarte, perpassando "linguagem oral/textos/frases/ palavras/letras", caminha-se do todo para as partes, o que pode dar a falsa impressão de tratar-se de um modelo de interpretação analítico ou global. Todavia, destaque-se que o movimento dedutivo contém, por interioridade, o movimento indutivo. Por conseguinte, no ensino da escrita há que se diferenciar, a cada momento do processo, aquilo que se impõe como fundo em relação ao que se impõe como figura. A linguagem oral, os textos e as frases, em suas expressões globais, representam o fundo sobre o qual a alfabetização ocorre, e tem como figura as relações entre fonemas e grafemas. A partir do momento em que o domínio da relação entre grafema e fonema se concretiza, linguagem oral, textos e frases passam a ser figura no estudo gramatical da linguagem escrita enquanto fonemas e grafemas tornam-se fundo. Com isso afirmamos o princípio metodológico dialético para a orientação do ensino da escrita, tendo em vista superar as perspectivas que unilateralizam ora enfoques analíticos ora os enfoques sintéticos em alfabetização.

\section{Considerações Finais}

Reiteramos a natureza cultural do desenvolvimento humano tendo em vista evitar quaisquer naturalizações acerca do processo de aquisição da escrita. Em anuência com Luria (2016) descartamos que haja um percurso natural e linear de etapas no que tange à escrita, a exemplo do proposto por Ferreiro e Teberosky (1985). Para elas, a aquisição da escrita tem um caráter evolutivo e perpassa a formulação espontânea de hipóteses que a criança elabora em seu contato com a mesma. Haja vista que a escrita é uma objetivação humana dada à apropriação pelos sujeitos particulares, portanto, uma aquisição mediada intencional e sistematicamente pelo outro que a domina, não precisamos nem devemos esperar que os alunos construam solitária e 
espontaneamente suas hipóteses de escritas, pois “... por mais expostas que as crianças estejam ao universo cultural da escrita, o processo de apropriação deste conhecimento passa necessariamente pela mediação do outro" (Stemmer, 2010, p. 132), ou seja, é preciso que os alunos sejam ensinados a ler e a escrever.

Deste modo, destacamos que o professor exerce função imprescindível para que os alunos se apropriem da língua escrita nas diferentes etapas, já que tal apropriação não acontecerá de forma espontânea ou natural. É preciso que o docente planeje suas aulas considerando a tríade proposta por Martins (2013): conteúdo-forma-destinatário. Isto significa intencionalidade no ato de ensinar, pois levando em conta esta tríade o professor, para promover o desenvolvimento de seus alunos, necessita: dominar os conteúdos a serem ensinados, tendo ciência que tais conteúdos não devem se restringir a aspectos fortuitos e cotidianos, portanto, trata-se de conteúdos científicos, artísticos e filosóficos; conhecer a zona de desenvolvimento real e iminente dos aprendizes, ou seja, aquilo que o aluno já domina e o que ainda está em vias de formação; e por último, pesquisar e/ou criar a melhor forma para ensinar, tendo em vista o que e a quem, ou seja, o que (conteúdo) deve ser ensinado e as especificidades do desenvolvimento e necessidades de aprendizagem de quem aprende (destinatário). Na Educação Infantil ou no Ensino Fundamental a aprendizagem da língua escrita depende, dentre outros aspectos, das “... condições de realização do ensino e [d]a exímia formação de seus professores" (Martins \& Marsiglia, 2015, p. 48).

Destaque-se ainda que a psicologia histórico-cultural não é alheia ao aclaramento da trajetória culturalmente condicionada que pauta a aprendizagem da escrita na sociedade contemporânea, representando-a pelas etapas da escrita pré-instrumental, escrita gráfica não diferenciada; diferenciada, pictográfica e escrita simbólica. Com base em tais proposições lurianas, tomamos como objeto de análise a transição da escrita pictográfica em direção à escrita simbólica, propondo então a existência das subetapas da escrita pré-gráfica e do simbolismo gráfico, na base das quais a escrita simbólica edifica-se. A nosso juízo, a compreensão do processo cultural de desenvolvimento que corresponde à complexificação da linguagem oral sob a forma de linguagem interna e desta em relação à escrita representa um dos maiores contributos da psicologia histórico-cultural para a alfabetização, pois, localiza-a no bojo do desenvolvimento psíquico mais amplo, que ultrapassa em muito supostos estágios naturalmente condicionados e o momento pontual no qual se visa ensinar alguém a ler e escrever. Sob essa premissa, a periodização histórico-cultural do desenvolvimento da escrita não possui um caráter diagnóstico ou prescritivo, apontando, meramente, os meandros pelos quais os sujeitos particulares internalizam esta objetivação humana, presente no plano interpessoal e interpsíquico. Sendo assim, em sua base não reside outra coisa, senão, a qualidade da inserção cultural do sujeito.

\section{Referências}

Cagliari, L. C. (2009). Alfabetizando sem o bá-bé-bi-bó-bu. (2a ed.). São Paulo: Scipione.

Dehaene, S. (2012). Os neurônios da leitura. Porto Alegre: Penso.

Ferreiro, E.; Teberosky, A. (1985). Psicogênese da língua escrita. Porto Alegre: Artes Médicas.

Fischer, S. R. (2006).História da leitura.São Paulo: Editora UNESP.

Fischer, S. R. (2009). História da escrita. São Paulo: Editora UNESP.

Instituto Paulo Montenegro (2011). Inaf Brasil 2011: Principais resultados. Recuperado: 17 dez. 2013. Disponível: http:// www.ipm.org.br/download/inf_resultados_inaf2011_ver_final_ diagramado_2.pdf.

Instituto Brasileiro de Geografia e Estatística. (2015). Educação. Recuperado: 20 jun. 2016. Disponível: http://brasilemsintese.ibge. gov.br/educacao.html?id=3260.

Instituto Nacional de Estudos e Pesquisas Educacionais Anísio Teixeira. (2014). Resultados Prova ANA. Brasília, DF: INEP. Recuperado: 20 jun. 2016. Disponível: http://portal.inep.gov.br/ web/guest/educacao-basica/saeb/resultados.

Instituto Nacional de Estudos e Pesquisas Educacionais Anísio Teixeira. (2015). Sobre a ANA. Brasília, DF: INEP. Recuperado: 15 set. 2017. Disponível: http://portal.inep.gov.br/educacao-basica/ saeb/sobre-a-ana.

Leontiev, A. N. (1978). O desenvolvimento do psiquismo. Lisboa, Livros Horizonte.

Luria, A. R. (1979). Curso de Psicologia Geral. Rio de Janeiro: Civilização Brasileira.

Luria, A. R. (1981). Fundamentos da neuropsicologia. Rio de Janeiro: LTC.

Luria, A. R. (2001). Pensamento e linguagem: as últimas conferências de Luria. Porto Alegre: Artmed.

Luria, A. R. (2016). O desenvolvimento da escrita na criança. In: Vigotskii, L. S.; Luria, A. R.; Leontiev, A. N., Linguagem, desenvolvimento e aprendizagem (12a. ed., pp. 143-189). São Paulo: Ícone.

Martins, L. M. (2013). O desenvolvimento do psiquismo e a educação escolar: contribuições à luz da psicologia histórico-cultural e da pedagogia histórico-crítica. Campinas, SP: Autores Associados.

Martins, L. M.; Marsiglia, A. C. G. (2015). As perspectivas construtivistas e histórico-críticasobre o desenvolvimento da escrita. Campinas, SP: Autores Associados. 
Mortatti, M. R. L. (2000). Os sentidos da alfabetização: São Paulo / 1876-1994. São Paulo: Editora UNESP.

Saviani, D. (2012). Pedagogia Histórico-Crítica: Primeiras aproximações. (11a. ed.). Campinas, SP: Autores Associados.

Scliar-Cabral, L. (1997). Psicolinguística e neolinguística. Cadernos de Estudos Linguísticos, 3, 37-48.

Stemmer, M. R. G. (2010). A educação infantil e a alfabetização. In: Arce, A.; Martins, L. M. (Orgs.), Quem tem medo de ensinar na educação infantil?: em defesa do ato de ensinar (pp. 125-145). Campinas, SP: Alínea.

Vygotsky, L. S. (1995). Obras escogidas. Tomo III. Madrid: Visor.
Vygotsky, L. S. (1997). Obras escogidas. Tomo V. Madrid: Visor.

Vygotsky, L. S. (2001). Obras escogidas. Tomo II. Madrid: Visor.

Vygotsky, L. S. (2006). Aprendizagem e desenvolvimento intelectual na idade escolar. In: Vygotsky, L. S.; Luria, A. R.; Leontiev, A. N., Linguagem, desenvolvimento e aprendizagem (10a. ed., pp.103118). São Paulo: Ícone,

Vygotsky, L. S.; Luria, A. R. (1996). Estudos sobre a história do comportamento: símios, homem primitivo e criança. Porto Alegre: Artes Médicas.

Vygotsky, L. S.; Luria, A. R. (2007). El instrumento y el signo en el desarrollo del niño. Madrid: Fundación Infancia y Aprendizaje.

Recebido em: 24 de maio de 2017 Aceito em: 17 de outubro de 2017 unrestricted use, distribution and reproduction in any medium, provided the original article is properly cited. 